\title{
The Multilingual Education (MLE) network phenomenon: advocacy and action for minoritized language communities
}

\author{
Barbara Trudell
}

Correspondence:

barbara_trudell@sil.org

SIL Africa, Nairobi, Kenya

\section{Springer}

\begin{abstract}
This article examines a new phenomenon in language activism variously called the multilingual education working group or the multilingual education network, and abbreviated as MLEN. After an analysis of the conceptual and organizational contexts for these activist groups, the six MLENs in existence as of 2013 are described. The groups are then analyzed for particular characteristics and trends which they demonstrate.
\end{abstract}

\section{The conceptual context of MLENs}

Most language change is unplanned and organic in nature. Language, as an artefact of human communication, changes to meet changing communication needs and desires. However, because language is such a crucial piece of human identity and communication, language use can also be the target of intentional action. Language planning is the expression of intentional language change - either to the benefit or the detriment of the language(s) involved and their speakers. Language development describes a positive change in language use and involves increasing the domains of use of the language (Haugen 1966).

In a multilingual setting, languages considered to be 'minority' or 'minoritized are often vulnerable on a number of levels. Language status in a society parallels the social and political status of its speech community, and language endangerment is in most cases a phenomenon visited on the marginalized or subordinated minority and ethnic groups (May 2008, p. 4). These languages themselves generally lag behind in language development processes such as linguistic analysis, establishment of an orthography, vocabulary and development for use in wider contexts. For the communities of speakers of these languages, language development is a crucial component of educational success, maintenance of culture, political participation and a host of other perceived goods. The local languages in these communities are often unwritten as yet; language development in these cases is a substantial undertaking, with specific policy, attitudinal and resourcing requirements. These communities also do not generally enjoy the degree of political or social influence needed for their language concerns to be taken seriously at national or international levels.

(c) 2014 Trudell; licensee Springer. This is an Open Access article distributed under the terms of the Creative Commons Attribution License (http://creativecommons.org/licenses/by/4.0), which permits unrestricted use, distribution, and reproduction in any medium, provided the original work is properly credited. 
Language communities also typically lack the organizational structures and political influence to bring about language development outcomes for themselves. For that reason, language development involves a range of actors, from national and international institutions to the most rural language community members.

Among these actors, the central role of the state in language development is generally assumed. Indeed, among language rights activists, the state is seen as the organ that is ultimately responsible for creating an environment in which minority languages can survive (Grin 2005, p. 457). However, as Simala (2002) has noted, assigning the dominant role in language planning and development to the state can be problematic. Crawhall (1999, p. 331), assessing the language situation of the San and Khoe communities of South Africa, describes the optimal role of the state as well as its limitations where language maintenance is concerned:

It is clearly the responsibility of the state to remove barriers to the use of San and Khoe languages in schools and to create an enabling policy environment that will allow people access to traditional natural resources upon which their language and identity rest. However, it is unrealistic to expect the state to be able to directly intervene in the sociological processes that cause language death.

In this environment, the gap between the state and the language community may be filled by a variety of language activists. One fairly new entry into this space is the "Multilingual Education Network" or "Multilingual Education Working Group" (abbreviated in this article as the MLEN). As of late 2013, six are active in Asia, Africa, Europe and the United States.

All of the MLENs so far have developed independently, responding to local interest and issues, although certainly the earlier networks did give some helpful examples to the shaping of those developed later. A few global organizations have been involved in the development of each MLEN, such as Save the Children, UNESCO and SIL International. However, the common involvement of these organizations has not been orchestrated ahead of time, but has been a result of the concerns and priorities of these organizations' national-level offices.

MLEN members are typically scholars, consultants, personnel working in NGOs and international donor organizations, and government education personnel - all of whom share a common concern for the educational, linguistic and cultural challenges faced by minority language communities. Located in the capital cities of their respective countries, MLENs tend to attract people with a national and international perspective, rather than locally-focused organizations or individuals. The aims of the MLENs are contextually shaped, but they are also quite similar as will be seen below.

To some extent, MLENs can be located in the context of civil society as it plays out in national contexts. Civil society is usually understood to be the collective intermediary between the individual and the state. It exists outside the state, and is meant to exercise restraint on the state (Whaites 2000). Lewis and Kanji (2009, p. 128) observe that: 
Civil society groups exist on the outer edges of the institutional system through which state power is legitimized, but at the same time civil society forms an arena in which various social groups can organize in order to contest state power.

Lewis and Kanji also note that the origins of civil society are primarily political, not technical. This observation has particular relevance for the MLEN, the goals of which are primarily political (in terms of advocacy) - though they are also technical (in terms of research and training materials development, and so on).

\section{Siting MLE networks in a range of language-related action}

The role and character of the MLEN can be further understood in the broader context of language-related action. Such action, whether policy oriented or development oriented, takes place at a number of sites in the sociolinguistic milieu. It helps to provide the concerted institutional support needed "if [minority] languages are to be empowered so that they are able not only to maintain themselves but also to flourish as effective media for their users and vehicles of their solidarity and self-identity" (Batibo 2005, p. 121).

\section{The state}

Parastatal national commissions on language, institutes of national languages, and national language academies can be found across the world. Some African examples include:

i. Benin's Center for Applied Linguistics (CENALA), which has the responsibility for developing Benin's languages for broader use (Trudell and Reeder 2006);

ii. South Africa's Pan South African Language Board (PanSALB);

iii. Senegal's Académie des Langues Nationales (Trudell 2008);

iv. The Malian government's Direction Nationale de l'Alphabétisation Fonctionnelle et de la Linguistique Appliquée (DNAFLA; Traoré 2001).

These organizations are responsible for setting a policy environment for language use and support and to some extent for implementation of those policies as well. Obviously, the agenda of such state-sponsored organizations is a national one, and is vulnerable to politically-oriented critique.

\section{International organizations}

Important language activism takes place beyond state borders as well. For decades, Nongovernmental and intergovernmental organizations have played a significant role in advocacy on behalf of minority language maintenance and use. The United Nations Educational, Scientific and Cultural Organization (UNESCO) is the premier such organization, having gone on record as early as 1953 as a defender of the use of minority languages in school (UNESCO 1953). Indeed, Ogechi (2003) identifies the United Nations Universal Declaration of Human Rights, promulgated in 1948, as a primary pillar of language rights. UNESCO's pro-local language stand has continued through the decades, including significant support for African languages specifically (Bühmann and Trudell 2008; Kioko et al. 2008).

In Africa, a number of other international organizations are actively involved in language activism. The African Union has been active in this area since 1976. The primary focus for AU interest in African languages is now the African Academy of 
Languages (ACALAN); ACALAN's plan for establishing a "counter-hegemonic strategy" for the promotion of African languages, as expressed by Alexander (2008, p. 255), is truly inspiring.

International and national-level non-governmental organizations have also played significant roles in language-related action in Africa. Examples include SIL International, the Association for the Development of African Languages for Education, Science and Technology (ADALEST), the Molteno Institute for Language and Literacy, the Centre for the Advanced Study of African Societies (CASAS), and the Project for Alternative Education in South Africa (PRAESA). These organizations carry out research and advocacy activities, highlighting the pedagogical, social and cultural benefits of African language development and use. Certain education NGOs such as Save the Children also play important roles in advocacy and implementation. Bilateral donors such as Deutsche Gesellschaft für Internationale Zusammenarbeit (GIZ, formerly GTZ) and the Norwegian Agency for Development Cooperation (NORAD) have also had significant impact on language use policy and practice in certain countries.

\section{The language committee}

The local language committee (also called a language association) is an important community-level actor. Successful language development requires extensive participation by the language's owners, the language community; and that is where the language committee finds its role as an institution built on locally expressed language activism. The language committee takes on the activist role of speaking to, and for, the community where its language is concerned. As Adegbija (2004, p.237) has, in Nigeria:

Vibrant language activism promotes the maintenance of a language, especially a minority indigenous language. Activism gives a language a voice that raises the awareness of the speakers to the fact that they need to have a stake in the growth, development and survival of their language.

The language committee channels local motivation, providing a structured means for stakeholder participation in the development of their language (Simala 2002). As a local, organized vehicle for language activism, the language committee identifies with and capitalizes on the desire of the community to both maintain its identity and benefit from the education and development opportunities that exist.

\section{Individual activists}

Examination of language activism also uncovers a number of individual language activists, members of the local elite who spearhead the development and promotion of the local language. Ager (2001, p.133) describes these leaders this way:

The language activist who inspires others to act on language matters is a recognisable individual who often makes his or her views on language known at the same time as views on a variety of related matters.

Several examples of such activists may be found in literature about language development in Africa. One prominent example is the Kenyan author, Ngugi wa Thiong'o, who 
for years has championed the use of African languages as an issue of identity as well as learning and development (cf. Ngugi 2005).

\section{MLENs as of 2013: what they do}

Below is a description of the focus of MLENs in various regions of the world.

\section{Bangkok}

The Bangkok MLE Working Group, based in Bangkok, is the oldest of the MLE working groups. Its founding members include UNESCO, the United Nations Children's Fund (UNICEF), the Southeast Asian Ministers of Education Organization (SEAMEO), Save the Children UK, SIL International, Mahidol University, and CARE International. The group actually began as the planning group for a 2003 international conference on language and education, held in Bangkok. Since then the group has held three more such conferences in 2008, 2010 and 2013.

The group's stated purpose is "identifying the major needs in nurturing a multilingual education movement throughout Southeast Asia and coordinating human and financial resources to help meet those needs". The group's current terms of reference (written in November 2009) state that:

The goal of the Asia Multilingual Education Working Group (MLE WG) is to remove barriers of access to quality education for ethnolinguistic communities through coordination of technical and substantive support to multilingual education initiatives and related policy advocacy throughout the Asia region.

The functions which the group has set for itself demonstrate its Asia regional focus. They include the coordination of regional development actors' efforts to support MLE, capacity building and networking with national-level initiatives in language and education, and advocacy for supportive policies and practices that facilitate better integration of language issues in education and development.

As of 2013, the group's areas of focus are:

i. Development of an MLE mapping and gap analysis: Develop a framework for conducting a situational analysis documenting key issues, actors and activities shaping the context for ethnolinguistic communities and MLE in the region.

ii. Development of an MLE assessment framework: Identify principles and good practices in monitoring, evaluating and reporting on the impact of multilingual education programs on improving educational attainment of ethnolinguistic communities.

iii. Hosting language and education conferences.

The group is led by a chair and a secretariat, positions which rotate among the membership. The group meets four times a year.

\section{Washington DC}

The Washington DC-based MLE Working Group began in mid-2007. Its participants include staff from institutions such as Research Triangle International (RTI), FHI 360 
(formerly the Academy for Educational Development), the International Reading Association, SIL International, Save the Children US, the World Bank, the United States Agency for International Development (USAID) and the Center for Applied Linguistics, along with several independent education consultants. The group focuses on advocacy among agencies and organizations in the Washington area, and counts up to 30 members.

The three current focus areas of the group are disseminating research-based evidence and user-friendly resources and information about MLE; providing support to key partners and stimulating collaboration among academics, practitioners and others; and conducting advocacy to influence key stakeholders.

The group has also recently taken new energy and direction, identifying itself as "locally based and globally oriented". This global focus is played out in, among other things, the creation of a resource and collaboration website that serves all of the MLE networks around the world (http://www.mlenetwork.org).

\section{London}

The London-based MLE Working Group formed in 2007 is modelled on the Washington DC group. The group includes both scholars and non-governmental organization (NGO) staff, including representation from Save the Children UK, the International Development Network, SIL International, Minority Rights Group International, the University of Leeds and the Open University. The London group adopted the following vision statement:

The London working group on multilingual education promotes linguistically and culturally appropriate education to improve access and learning in nations throughout the world.

The group also has taken on the functions of advocacy, coalition building and knowledge generation and exchange. The group meets two to three times per year. The group is currently co-chaired by Save the Children UK, and SIL International.

Currently, this group's goals include advocacy with the UK Forum on International Education and Training (UKFIET), engagement with various implementers of the Early Grade Reading Assessment to advocate for the inclusion of language as a variable, and encouraging UNESCO to consider a conference on MLE in developing countries. There is also a strong information-sharing function in this group, including updates on the status of multilingual education worldwide.

\section{Nairobi}

The Nairobi-based MLE Network of Kenya was the first African MLEN to form; it is also the first MLEN with a national focus. Although its original intention was to be regional in scope, the reality is that its members are primarily Kenya-focused. Indeed, the goal of the network, as stated in its terms of reference, is to influence practice in the Kenyan classroom where language of instruction is concerned.

The Network traces its beginnings to a one-day research seminar on language and education, held in 2006, hosted by Bible Translation and Literacy (BTL) Kenya and SIL Africa Area and funded partly by the Commonwealth Education Fund. The 15 or so scholars who shared their work that day saw the value of such a meeting; but it was not until two years later that the initial meeting of what would become the MLE Network of Eastern Africa was held. 
The group that met in early 2008 to form the MLEN included not only scholars, but also representatives of national and international education NGOs. Representatives of national government education offices also became part of the network, as did UNESCO. The current membership of this network is around 25 people. One unique feature of this network is the strong representation from five Kenyan universities; at least $40 \%$ of the attending members are on the academic faculty of one of these universities. Other Network members serve on the staff of organizations such as World Vision, FHI 360, Save the Children, UNESCO, United Bible Societies (UBS) Africa Area, the National Book Development Council, Partners in Literacy Ministries (PALM), Bible Translation and Literacy (BTL Kenya), the Bible Society of Kenya, SIL Africa Area, the Department of Adult Education and the Kenya Institute of Education.

Right from the start, the concern of the MLEN has been to influence practice at all levels. They are not interested in producing yet one more scholarly study that goes in someone's file drawer, and they are not interested in endless talks amongst themselves which amounts to "preaching to the converted". The goal has been to find ways to make a difference in Kenyan classrooms and school systems where language of instruction is concerned.

The four themes that shape the activities of the MLEN in Nairobi are:

i. Advocacy: the group published an advocacy book in 2008, called Language and Education in Africa: Answering the Questions. Authored by several MLEN scholars and edited by the entire group, the book was printed by UNESCO Nairobi. A French version of the book is awaiting publication.

The MLEN is active in participating in national-level celebrations of International Literacy Day (ILD, 8 September) and International Mother Language Day (IMLD, 21 February). Beginning around 2011, the MLEN has participated in activities each year to mark these days, including radio talk shows, celebratory events and newspaper advertisements. In addition, the MLEN staffed a booth at the Africa preparation meetings for the UN's 6th International Conference on Adult Education (CONFINTEA VI) in late 2008, providing information and materials to interested meeting participants.

ii. Knowledge generation and knowledge sharing: from the beginning of the MLEN, guest speakers who are experts in the language and education field have been invited to give presentations at the meetings. Speakers so far have come from Canada, South Africa, Tanzania and Uganda. In addition, the members of the MLEN themselves have given presentations on various aspects of the field. Another major project of the MLEN has been the production of an MLE manual for teacher trainers, to be used in teacher training institutions and in-service events. The manual has been used as a resource for teacher training in Kenya and Ethiopia; unfortunately, it has not been possible so far to find a funder to publish the manual in its entirety.

iii. Coalition building: the gathering of MLEN members twice a year has led to strengthened alliances among the institutions represented there.

iv. Tracking and supporting research: this theme of the MLEN has had less success so far than the other three. Although a number of useful research topics have been identified, research can be costly and it has not proven easy to mobilize research efforts around the topics identified. However, members of the network do carry out research on their own accord, and they share that research with the rest of the group as appropriate. 
The Network is led by a steering group, made up of 4-6 members of the Network. The steering group leads the overall direction of the MLE Network, plans meetings and oversees the use of funds donated for the purpose of running the MLE Network.

One of the primary means by which the MLE Network works is by the formation of task teams. Task teams consist of MLE Network members with particular skills and interest in the task being articulated. Task teams are responsible for such tasks as developing advocacy materials, authoring training materials, staffing information booths at events, developing key documents for the MLE Network, and so on.

The MLE Network normally meets twice per year. Special meetings may be held in addition to the two regular meetings, when the input of all the MLE Network members is needed on a particular project.

\section{Kampala}

The Uganda MLE Network began in July 2009, when a small group of NGO leaders and educationists in Uganda met to discuss the challenges in education connected to language, and specifically the use (or neglect, in many cases) of the home language. This original forum has now grown and become the Uganda Multilingual Education Network.

The forum includes representatives from Save the Children, Mango Tree Educational Enterprises, UNESCO, UNICEF, the Uganda National Curriculum Development Centre, Kyambogo University, Makerere University's Institute of Languages, Uwezo Uganda, Straight Talk Uganda, The Forum for Education NGOs in Uganda, and the Dutch development organization, SNV. The list of interested participants has grown to 60, and the MLEN meets every two months in Kampala.

The core mission of the group is:

To ensure and promote home language based MLE (learning) in Uganda, in effective support of the policy of the Uganda Ministry of Education and Sports and each selfdefined language community, through home language development.

The MLEN Uganda carries out this mission through advocacy, awareness raising, networking, technical assistance, and advising. The group has expressed five core values: language as identity, dialogue between key stakeholders, strong partnership, efficiency without unnecessary duplication, and resourcefulness.

Among its advocacy activities, the MLEN is active in reviewing and critiquing national policy that is relevant to the use of local languages in schools; for example, in 2012 a government move to remove the teaching of Ugandan languages from the national secondary school curriculum was met with energetic dialogue and advocacy from MLEN members.

\section{Addis Ababa}

The newest MLEN, the MLE Network of Ethiopia, was launched on 9 October 2012. This launch was the culmination of two years of processing and thinking by the Ministry of Education and the Ministry of Culture and Tourism, along with interested NGOs and universities.

The founding members of the network members include the Ministry of Education, the Ministry of Culture and Tourism, Addis Ababa University, Wollayetta Sodo University, the Ethiopian Multilingual and Multi Cultural Professionals Association, Mizan Teppi 
University, USAID Ethiopia, the Southern Regional Education Bureau, the Southern Bureau of Culture and Tourism, and SIL Ethiopia. The network is intended to be open to any organization working on education in the country.

The network members are now engaged in developing the vision, mission, objectives, tasks and action plan of the network.

\section{Issues arising}

The MLENs described above share a number of commonalities, including the dynamics of their genesis. However, a few important distinctions exist as well, as discussed below.

\section{Why these networks?}

Why have these networks evolved? What has fuelled such an international interest in such groups? Several reasons come to mind:

i. These MLENs fill a space for national or international-level interest groups where language and education are concerned. A number of large international organizations are known for their advocacy on behalf of education for minoritized ethnic communities (e.g. UNESCO, SIL, Save the Children), but the MLENs provide a space for individual activists and local NGOs - as well as representatives of the larger organizations to meet together and share ideas.

ii. The MLEN appeals to both educationists and linguists. This dual-discipline interest populates the MLENs with a wider variety of NGOs, government organizations and individuals than a single disciplinary focus would do.

iii. The MLENs typically facilitate a very positive synergy among scholars, civil society organizations and the state. For example, the membership of the Nairobi MLEN includes people from 5 Kenyan universities, at least 6 NGOs or intergovernmental organizations, and at least two government education agencies. This allows the group to engage with multi-faceted strategies of advocacy and resource development.

iv. The MLEN meetings provide unusual networking opportunities for people whose goals and interests align but who would not otherwise be in contact very often. It is common to find that the relationships built in an MLEN context have led to collaborative action between two or more of the network members.

One might wonder why these organizations have emerged now. As has been noted, these MLENs all had their genesis since 2003, in a time in which language and education issues are arguably the most prominent that they have been in a very long time. In the era of unmet EFA goals and MDGs, MLE currently holds real promise for improving access to quality education - a promise which is beginning to be acted on in the two-thirds world.

More immediately, the MLEN idea as it was modelled by the earlier groups served as an inspiration for the establishment of the later groups. However it is important to note that each of these groups developed distinctly, based the context and the individual membership of each group. There is no template or plan for an MLEN as such. 
Given that fact, it is very interesting that the groups have formulated such similar goals and strategies. This supports the notion that the energy that drives the MLEN does not come from laws or international agreements, but rather from more local experience as lived by the network members. The attraction of an MLEN has to do with the member's own beliefs and values regarding the minority people groups of the world, and the benefits of being with others who share those beliefs and value.

\section{How the groups are distinct}

One major distinction between the various MLENs is that some groups have been established with an international focus while others are nationally focused. In the case of the Washington and London groups, the focus areas of the MLEN are not on the same continent as the group itself because they concentrate largely on the African continent. As a result, these groups tend to focus on broader outcomes, intended to benefit people who are not in the USA or UK.

In the cases of Nairobi, Kampala and Addis Ababa, the intended outcomes are specific and local; in some ways these concrete outcomes are harder to achieve, but they are also deeply inspiring and motivational to the membership. Where the MLEN consists primarily of citizens of the country, advocacy and resource development take on strong personal significance.

The Bangkok MLEN has a more regional flavor, with quite a few representatives of regional and international NGOs, intergovernmental organizations and donors who share regional education concerns. This make-up accounts for this group's ability to repeatedly sponsor large-scale, international conferences in the region.

The distinct nature of each MLEN - the local motivation that has led to its formation, the ways in which it carried out its goals - is an indication of the independence of each of these groups. No one group is central to the MLEN movement, and no one group leads the others. However, it is undeniably true that links between the networks would be helpful to all concerned, for a variety of reasons. The initiative of the Washington MLEN to establish a website which serves as a knowledge bank and a link between the various MLENs could provide a space for such links to grow.

\section{Growth and sustainability}

One of the strengths of the MLENs is the role they play in allowing networking and synergistic action among the network members. The professional and personal benefits to meeting as MLENs enhance the sustainability of the groups.

The active membership of the MLENs varies, often depending on the amount of time each member has available to dedicate to it in a given month or year. Individual interest, not representation of an agency or organization, seems to be the overriding reason for members to continue to participate.

The issue of legal registration is rising in some cases. For the Nairobi group at least, legal registration would allow the MLEN to receive funding from outside sources. However, in the limited time that Nairobi MLEN members have available to dedicate to the network, taking part in the meetings and related project activities appears to be of higher priority than attempting to obtain legal registration. It is not clear whether 
MLENs actually need legal recognition to ensure their sustainability, particularly if outside funding is not crucial to the group's functioning.

Certainly, it seems that interest in MLENs is spreading. At least in African contexts, the idea appears to be attractive to a range of language specialists and educationists. As of this writing, discussions have been held regarding establishing MLENs among UNESCO partners in West Africa.

\section{Conclusion}

MLE networks and working groups are a worldwide expression of activism on behalf of education for minoritized language communities. As they have been supported by international NGOs, intergovernmental organizations, donor agencies and national government agencies, MLENs have become important sites for collaboration between individual scholars and agency or state personnel; international collaboration has also been seen in the establishment of the global MLE Network website. The heart of advocacy and action is commitment, and MLENs are providing a place for committed individuals to collaborate effectively and enhance their ability to make a difference.

Competing interests

The author declares that she has no competing interests.

Received: 24 February 2014 Accepted: 15 July 2014

Published: 23 July 2014

\section{References}

Adegbija, E. 2004. Language policy and planning in Nigeria. Current Issues in Language Planning 5(3):181-246. Ager, D. 2001. Motivation in language planning and language policy. Clevedon: Multilingual Matters Ltd. Alexander, N. 2008. Creating the conditions for a counter-hegemonic strategy: African languages in the twenty-first century. In Globalization and language vitality: Perspectives from Africa, ed. CB Vigouroux and S Mufwene, 255-271. London: Continuum.

Batibo, H. 2005. Language decline and death in Africa: Causes, consequences and challenges. Clevedon: Multilingual Matters Ltd.

Bühmann, D, and B Trudell. 2008. Mother tongue matters: Local language as a key to effective learning. Paris: UNESCO.

Crawhall, N. 1999. Going to a better life: perspectives on the future of language in education for San and Khoe South Africans. International Journal of Educational Development 19(1999):323-335.

Grin, F. 2005. Linguistic human rights as a source of policy guidelines: a critical assessment. Journal of Sociolinguistics 9(3):448-460.

Haugen, E. 1966. Dialect, language, nation. American Anthropologist 68: 922-935.

Kioko, A, J Mutiga, M Muthwii, L Schroeder, H Inyega, and B Trudell. 2008. Language and education in Africa: Answering the questions. Nairobi: UNESCO.

Lewis, D, and N Kanji. 2009. Non-governmental organizations and development. London: Routledge.

May, S. 2008. Language and minority rights: Ethnicity, nationalism and the politics of language. New York: Routledge.

Ngugi, WT. 2005. Europhone or African memory? The challenge of the pan-Africanist intellectual in the era of globalization. In African intellectuals: Rethinking politics, language, gender and development, ed. T Mkandawire, 155-164. Dakar and London: CODESRIA and Zed Books.

Ogechi, N. 2003. On language rights in Kenya. Nordic Journal of African Studies 12(3):277-295.

Simala, IK. 2002. Empowering indigenous African languages for sustainable development. In Speaking African: African languages for education and development, ed. FR Owino, 45-53. Cape Town: CASAS.

Traoré, S. 2001. La pédagogie convergente: Son expérimentation au Mali et son impact sur le système educatif. Paris: UNESCO IBE.

Trudell, B. 2008. Practice in search of a paradigm: Language rights, linguistic citizenship and minority language communities in Senegal. Current Issues in Language Planning 9(4):395-412.

Trudell, B, and J Reeder. 2006. Discourses of authority and stakeholder perspective: Processes of language development in Benin. Conference on Languages and Education in Africa, University of Oslo, 19-22 June 2006.

UNESCO. 1953. The use of vernacular languages in education. Paris: UNESCO.

Whaites, A. 2000. Let's get civil society straight: NGOs, the state and political theory. In Development, NGOs and Civil Society, ed. D Eade, 124-141. Oxford: Oxfam GB.

doi:10.1186/s13616-014-0017-y

Cite this article as: Trudell: The Multilingual Education (MLE) network phenomenon: advocacy and action for minoritized language communities. Multilingual Education 2014 4:17. 